\title{
FLY LARVAE FOR WOUND MANAGEMENT: A MAGGOT MAKEOVER
}

Merilyn Geary and Richard Russell

Department of Medical Entomology

Institute of Clinical Pathology and Medical Research, Westmead

Maggots certainly have an image problem, but this humble insect - the immature stage of a housefly or blowfly - has much to offer the field of medicine in the 21st century. Maggots of certain fly species feed on necrotic flesh, and through this debriding activity can assist the healing of chronic soft-tissue wounds (such as pressure and venous stasis ulcers, diabetic foot infections, and postoperative wounds) that are resistant to surgical or antibiotic intervention. ${ }^{1,6}$ This article describes Maggot Debridement Therapy (MDT), an old remedy that has been revised and is now proven to be valuable for treating wounds unresponsive to conventional wound management.

\section{BACKGROUND}

For centuries, maggots were known to have beneficial effects on wounds. Ambroise Paré is credited to be the first to note his observations in the 1500s. Throughout military history, many other positive comments have been recorded by military surgeons in regard to maggotinfested wounds. However, it was not until the 1920s that therapeutic experimentation with maggots was instigated by William Baer, a clinical professor in orthopaedic surgery at the Johns Hopkins University in Baltimore, Maryland, whose unorthodox methods were successful in the treatment of osteomyelitis and pyogenic wounds. ${ }^{2}$ His method of MDT was adopted and routinely used in over 300 hospitals in the United States throughout the 1930s and early 1940s, but MDT was replaced with the introduction of penicillin and modern surgical procedures. $^{3-6}$

The 1980s brought an increase of bacterial resistance to antibiotics, and MDT was revisited as a procedure to assist in the treatment of nonhealing wounds that were resistant to antibiotics, or when surgical intervention was not an option. In recent years, simple procedures have been developed for the culture of disinfected maggots, and their placement within restrictive dressings into nonhealing wounds, to provide for cleansing of necrotic tissue and initiation of the healing process. ${ }^{78}$ Dr Ronald Sherman and associates from the Veterans Affairs Medical Center, California, pioneered the reintroduction of MDT. His clinical trials indicated that MDT was several times more efficient at debriding infected and gangrenous wounds (and in healing them more rapidly) than other modern nonsurgical treatments. ${ }^{1,6,9}$

While a range of reports describe good outcomes from MDT on different types of wounds, ${ }^{2,3,8,9}$ mystery still surrounds the unique way that maggots 'nurse' wounds as they actively consume dead tissue and fluids. In feeding, maggots secrete proteolytic enzymes that turn necrotic tissues into a semi-liquid form, which they ingest along with microorganisms that cause wound infections. As they cleanse the wound site, they exude an antibacterial agent that has a wide spectrum of activity against many resistant pathogens, while their proteolytic enzymes are also capable of digesting bacteria. The mechanical feeding of the maggots and the reduction of necrotic tissue changes the wound's environment from an acid to a more alkaline $\mathrm{pH}$, which assists in stimulating healthy granulated tissue. ${ }^{10,11}$

In the last 15 years, many thousands of patients with bedsores, leg ulcers, diabetic foot wounds, and postsurgical infections have been successfully treated by MDT. At present, health care facilities in the United Kingdom, Europe, and the United States now produce thousands of medicinal maggots per week for therapists. In the United Kingdom, MDT is now recognised as a procedure that can be officially prescribed and claimed on health care benefits. ${ }^{12}$

\section{MAGGOT DEBRIDEMENTTHERAPY IN AUSTRALIA}

Persistent requests from throughout Australia for sterile maggots encouraged the Department of Medical Entomology, Institute of Clinical Pathology and Medical Research (Westmead Hospital), to establish a colony of the sheep blowflies Lucilia cuprina and Lucilia sericata (the latter species being that most widely used for MDT), and to develop disinfection, transport and application procedures. Our techniques were based on Ronald Sherman's proven methodology, and we now supply disinfected Lucilia sericata maggots for local, interstate, and overseas patients. We are the sole supplier in Australia. Most of the requests we have serviced have involved patients where a final effort was being made to save limbs or to heal massive wounds, but the maggots have also been used in more routine wound management cases, including for burns.

The increasing incidence of soft-tissue wounds in nursing homes and hospitals, and the increasing prevalence of diabetes mellitus in the general community, suggest that antibiotic-resistant skin infections need to be addressed both at the level of population health and clinical practice. ${ }^{13}$

Although not all patients are suited to MDT therapy, it is an efficient, low-cost alternative method to cleanse and promote the healing of chronic soft tissue wounds before they progress to a stage where amputation is the only alternative. Although use of MDT is not yet widespread 
in Australia, perhaps a new image of maggots will emerge and they may become more widely recognised and accepted as an effective and economic means of treating wounds and saving limbs for patients in our health system.

For further information on Maggot Debridement Therapy visit

www.medent.usyd.edu.au/projects/maggott.htm (Institute of Clinical Pathology and Medical Research, Westmead, New South Wales, Australia); www.ucihs.uci.edu/com/pathology/ sherman/home_pg.htm (Veterans Affairs Medical Center, Los Angeles, California, United States): and www.larve.com (Princess of Wales Hospital, Bridgend, Wales, United Kingdom).

\section{REFERENCES}

1. Sherman RA. Maggot debridement in modern medicine. Infect Med 1998; Sept: 651-6.

2. Baer WS. The treatment of chronic osteomyelitis with the maggot (larva of the blow fly). J Bone Joint Surg Am 1931; 13: 438-75.
3. Child FS, Roberts EF. The treatment of chronic osteomyelitis with live maggots. New York State J Med 1931; 31: 937-43.

4. Teich S, Myers RAM. Maggot therapy for severe skin infections. South Med J 1986; 79: 1153-5.

5. Church JCT. Larva therapy in modern wound care: A review. Primary Intention 1999; May: 63-8.

6. Sherman RA, Hall MJR, Thomas S. Medicinal maggots: An ancient remedy for some contemporary afflictions. Ann Rev Entomol 2000; 45: 55-81.

7. Sherman RA. A new dressing design for use with maggot therapy. Plast Reconstr Surg 1997; 100: 451-6.

8. Thomas S, McCubbin P. Use of maggots in the care of wounds. Hosp Pharmacist 2002; 9: 267-71.

9. Sherman RA. Maggot therapy for treating diabetic foot ulcers unresponsive to conventional therapy. Diabetes Care 2003; 26: $446-51$.

10. Vistnes LM, Lee R, Ksander GA. Proteolytic activity of blowfly larvae secretions in experimental burns. Surgery 1981; November: 835-41.

11. Erdmann GR. Antibacterial action of myiasis-causing flies. Parasitol Today 1987; 3(7): 214-6.

12. LarvE Biosurgical Research Unit. Maggots on prescription [press release]. Available at www.larve.com (accessed 3 January 2005).

13. Bowler PG, Duerden BI, Armstrong DG. Wound microbiology and associated approaches to wound management. Clin Microbiol Rev 2001; 14: 244-69. 